\title{
The influence of Cistus incanus L. leaves on wheat pasta quality
}

\author{
Katarzyna Lisiecka $^{1} \cdot$ Agnieszka Wójtowicz $^{1}$ (D) Dariusz Dziki ${ }^{1} \cdot$ Urszula Gawlik-Dziki $^{2}$
}

Revised: 28 March 2019/Accepted: 24 June 2019/Published online: 11 July 2019

(C) The Author(s) 2019

\begin{abstract}
Modern nutritional trends and looking for functional food and dedicated products for various consumers are a source of inspiration for scientists to develop new pro-health supplemented foods with high quality. Therefore, the present study aimed to determine the selected properties of common wheat pasta fortified with dried Cistus incanus in amount from 1 to 5\% as a replacement of wheat flour. Pasta was made with a spaghetti shape and dried. Supplemented pasta was tested for total phenolics content, the total activity against DPPH, the ability to neutralize free radicals to ABTS and the antioxidant capacity reduction power, using various extraction procedures. Selected physicochemical properties of pasta were evaluated: cooking time, cooking weight, cooking loss, hardness and color profile of dry and cooked pasta in CIELab scale, as well as the sensory properties of supplemented products. The addition of $C$. incanus to fortify wheat pasta increased total phenolics content and antioxidant activity with some significant differences according to the extraction procedure used. Methanolic extraction was more efficient than buffer extraction. Increased addition of dry Cistus herb caused higher cooking weight, cooking loss and increased hardness of cooked pasta. Studies have shown that $C$. incanus addition had a slight effect on color change with the largest decrease in brightness, especially for cooked products. Finally, it was found that advisable
\end{abstract}

Agnieszka Wójtowicz

agnieszka.wojtowicz@up.lublin.pl

1 Department of Thermal Technology and Food Process Engineering, University of Science in Lublin, Głęboka 31, 20-612 Lublin, Poland

2 Department of Biochemistry and Food Chemistry, University of Life Sciences in Lublin, Skromna 8, 20-704 Lublin, Poland application of $C$. incanus addition to achieve nutritionally improved composition of pasta should not exceed 3\% due to the proper sensory characteristics.

Keywords Pasta $\cdot$ Cistus incanus $\cdot$ Extraction method . Antioxidant activity $\cdot$ Cooking quality

\section{Introduction}

New nutritional trends, as well as increased consumer awareness, caused the introduction into food health-promoting additives, especially into cereal products (Oniszczuk et al. 2016a, b). However, wide range of conventional products, from bread to baked products, extrudates, pasta and cereal-based foods are suitable for enrichment with functional additives as rich in e.g. fiber, polyphenols, as well as with increased antioxidant activity in order to achieve functional products (Biernacka et al. 2017; Bouasla et al. 2016; Oniszczuk et al. 2015a; Wójtowicz et al. 2018).

The main ingredient in traditional pasta processing is durum wheat, but also there are several pasta assortments made with common wheat or other raw materials. According to the low cost, simple production process and specific sensory attributes, pasta is a good example of versatility product suitable for the nutritional fortification (Sant'Anna et al. 2014). Wheat pasta enriched i.e. with herbs like oregano leaves (Boroski et al. 2011), vegetables like carrot pomace, spinach, tomatoes (Gull et al. 2015; Rekha et al. 2013), legumes like vicia faba bean, yellow pea, lentil, white bean, soy proteins (Wójtowicz and Mościcki 2014), pseudocereals like amaranth (CárdenasHernández et al. 2016), specific plants like wakame, carob or chia (Sęczyk et al. 2016) or by-products like bran or 
grape marc (Sant'Anna et al. 2014) are the examples of designedly supplementation with bioactive ingredients.

Cistus incanus L. is a herb plant that is rich in pro-health compounds. There is mentioned in the literature that herbal infusions and teas from $C$. incanus contain various polyphenolic compounds, in particular phenolic acids, flavonoids, especially flavone-3-ol derivatives as well as essential oils and resins (Viapiana et al. 2017). In the literature C. incanus is known also as Cistus creticus (Demetzos et al. 1997). Cistus creticus L. can be found in the Mediterranean and the Black Sea regions. The raw material is dried leaves which contain phenolic acids (gallic acid, ellagic acid, $p$-coumaric acid), flavonoids (quercetin, hyperoside, rutin), phytosterols, mucilages and tannins (Santagati et al. 2008). Essential oils found in $C$. creticus subsp. eriocephalus contain several active components as manyol-oxide (manjol), $\alpha$-kadinen, $\delta$-kadinen, bulnezol, wiridiflorol, ledol, $\alpha$-kopaen, $\beta$-selinen, kubenen and 13-epi-manyol oxide, and showed antibacterial properties (Demetzos et al. 1997). On the global market $C$. incanus is spread as dry herbs, teas and dietary supplements. In the literature it can be found information on tests performed on commercial teas, which confirm the presence of pro-health compounds and some benefits as the prevention of caries and periodontitis. It was confirmed also the antibacterial activity of $C$. incanus herbal tea on Streptococcus mutans (Viapiana et al. 2017). Móricz et al. (2018) used TLC-DB to obtain antibacterial profile of eleven $C$. incanus herbal teas and to guide isolation of bioactive compounds, rich exclusively in flavonoid aglycons, from the appropriate TLC zones. However, for $C$. incanus extracts it was not completed the evaluation of antibacterial and antifungal activity yet. But there are any information about food supplementation with this herb.

The aim of the study was to determine the effect of the addition of dried leaves of $C$. incanus on the total polyphenols content and antioxidant activity of healthpromoting compounds with application of various extraction methods, as well the effect of additive on selected properties of pasta products as the color profile, culinary quality and sensory characteristics of supplemented common wheat pasta.

\section{Materials and methods}

\section{Plant materials and pasta processing}

For pasta preparation wheat flour type 500 (PZZ Lubella Sp. z o. o. Sp. k., Lublin, Poland) was used as a basic raw material and water was added in ratio of 5:1. The chemical composition of wheat flour per $100 \mathrm{~g}$ was following: energy value $1485 \mathrm{~kJ} / 350 \mathrm{kcal}$, fat $1.4 \mathrm{~g}$ (including saturated fatty acids $0.4 \mathrm{~g}$ ), carbohydrates $73.0 \mathrm{~g}$ (including sugars $2.3 \mathrm{~g}$ ), fiber $2.8 \mathrm{~g}$, protein $10.0 \mathrm{~g}$, salt $0.03 \mathrm{~g}$ (producer data). As an additive the dried leaves of $C$. incanus herb were purchased (originated from Albania, distributor Malwa, Lubiszyn, Poland) and ground with a knife mill (Grindomix GM200, Retsch, Germany) for granulation of $<200 \mu \mathrm{m}$. The chemical composition of $C$. incanus per $100 \mathrm{~g}$, tested according to AACC methods (2011) was as follows: fat $1.36 \mathrm{~g}$, protein $7.88 \mathrm{~g}$, ash $7.70 \mathrm{~g}$, total fiber $63.74 \mathrm{~g}$, including $61.78 \mathrm{~g}$ of insoluble fiber and $1.96 \mathrm{~g}$ of soluble fiber.

Pasta fortified with $C$. incanus was prepared by replacing the wheat flour in the recipe with the addition of dried leaves in amounts of 1, 2, 3, 4 and 5\%. Dry ingredients were mixed in a stainless steel bowl with water up to $40 \%$ of dough moisture content and shaped for spaghetti with $2 \mathrm{~mm}$ forming die using a KitchenAid Artisan7 (Greenville, USA). The produced pasta was dried at $22{ }^{\circ} \mathrm{C}$ and $53 \%$ humidity for $24 \mathrm{~h}$ using Pasta Drying Rack KitchenAid 5KPDR (Greenville, USA) to the final moisture content of $12 \%$. The obtained products were kept closed and used for further research.

\section{Solvent extraction procedure}

The ground pasta $(0.5 \mathrm{~g}$, granulation below $300 \mu \mathrm{m})$ as well as dry herb of $C$. incanus were extracted separately with $5 \mathrm{~mL}$ of $50 \%$ methanol (the first type of extract-ME) and $5 \mathrm{~mL}$ of phosphate buffered saline $(0.01 \mathrm{M}$ phosphate buffer, $0.0027 \mathrm{M}$ potassium chloride, and $0.137 \mathrm{M}$ sodium chloride; the second type of extract-PBSE). Extractants were purchased from Sigma-Aldrich (Poznan, Poland). The obtained extracts were shaken for $30 \mathrm{~min}$ using a rotator Multi RS-60 operating at $5000 \mathrm{rpm}$ (Biosan, Riga, Latvia). The homogenate was centrifuged at the same velocity for $10 \mathrm{~min}$ at $4{ }^{\circ} \mathrm{C}$ using centrifuge MPW-352R (MPW, Warsaw, Poland). The extraction was carried out in double. The supernatants of ME and PBSE extracts were used for further analyses.

\section{Evaluation of polyphenols content}

The total polyphenols content was determined according to Singleton and Rossi (1965). In brief, $0.05 \mathrm{~mL}$ of $50 \%$ methanol, $0.1 \mathrm{~mL}$ of $\mathrm{H}_{2} \mathrm{O}$ and $0.4 \mathrm{~mL}$ of Folin reagent (in a ratio of 1:5 with distilled water) were added to $0.05 \mathrm{~mL}$ of extracts. After $3 \mathrm{~min}, 2 \mathrm{~mL}$ of $10 \%$ sodium carbonate was added to the mixture and vigorously shaken for $1 \mathrm{~min}$. In a reference sample, $0.05 \mathrm{~mL}$ of tested extract was replaced by $50 \%$ methanol. Subsequently after $30 \mathrm{~min}$ in dark place, the absorbance was measured at $712 \mathrm{~nm}$ using Microplate Spectrophotometer (Epoch 2, BioTek, USA) and the total phenolics content was expressed by a gallic acid 
equivalents (GAE) in $\mathrm{mg} / \mathrm{g}$ of dry weight (d.w.). Measurements were made in triplicate.

\section{Scavenging ability on 1,1-diphenyl-2-picrylhydrazyl (DPPH) radicals}

The scavenging ability on 1,1-diphenyl-2-picrylhydrazyl radical (DPPH) was carried out using the method presented by Harlina et al. (2018). Briefly, the extract $(10 \mu \mathrm{L})$ was mixed with $250 \mu \mathrm{L}$ of DPPH ethanol solution (concentration $0.2 \mathrm{mM} / \mathrm{L}$ ) and next shaken and rested for $15 \mathrm{~min}$. Subsequently, the absorbance was measured at $725 \mathrm{~nm}$ using Microplate Spectrophotometer (Epoch 2, BioTek, USA) from 0 to $15 \mathrm{~min}$ every $5 \mathrm{~min}$. Antiradical activity was expressed by $\mathrm{EC}_{50}(\mathrm{mg}$ d.w. $/ \mathrm{mL})$ as an effective concentration at which $50 \%$ of radicals were scavenged. For each sample and extract type measurements were made in triplicate.

\section{Scavenging ability on $\mathbf{2}, \mathbf{2}^{\prime}$-azino-bis(3- ethylbenzthiazoline-6-sulphonic acid) (ABTS) radicals}

The ability to neutralize free radicals against ABTS was carried out according to the methodology presented by $\mathrm{Re}$ et al. (1999). $10 \mu \mathrm{L}$ of the sample was added to $250 \mu \mathrm{L}$ of the ABTS radical. Then, the decrease in absorbance at a wavelength of $734 \mathrm{~nm}$ after 2 min was measured using microplate spectrophotometer (Epoch 2, BioTek, USA). Antiradical activity against ABTS was expressed by $\mathrm{EC}_{50}$ $(\mathrm{mg} / \mathrm{mL})$ as an effective concentration at which $50 \%$ of radicals were scavenged. For each extract type and sample recipe measurements were made triplicate.

\section{Ferric-reducing antioxidant power (FRAP)}

The reducing power was determined according to Oyaizu (1986). $0.5 \mathrm{~mL}$ of $200 \mathrm{mM}$ phosphate buffered saline extract and $0.5 \mathrm{~mL}$ of a $1 \%$ solution of potassium ferricyanide were added to $0.5 \mathrm{~mL}$ of the extract. The prepared mixture was insulated at $50{ }^{\circ} \mathrm{C}$ for $20 \mathrm{~min}$. Then, $0.5 \mathrm{~mL}$ of $10 \%$ trichloroacetic acid (TCA) was added and the mixture was rested for few minutes. $1 \mathrm{~mL}$ of that mixture was taken and mixed with $1 \mathrm{~mL}$ of deionized water and $0.2 \mathrm{~mL}$ of $1 \%$ iron (II) chloride. Absorption of electromagnetic wave energy was measured at $725 \mathrm{~nm}$ using Shimadzu UV-1280 UV-Vis Spectrophotometer. The high absorbance, expressed in $\mathrm{nm}$, was the result of high reduction power. FRAP antioxidant power was expressed by $\mathrm{EC}_{50}(\mathrm{mg} / \mathrm{mL})$ as an effective concentration at which $50 \%$ of radicals were scavenged. For each sample measurements were made in triplicate.

\section{Cooking quality of pasta}

The optimum cooking time (OCT) was established by cooking of $25 \mathrm{~g}$ pasta in $300 \mathrm{~mL}$ of boiling distilled water in a beaker. During cooking pasta strains were removed from a beaker at 30-s sequence and squeezed between two transparent plastic plates in triplicate. The time when the white centre core disappeared was reported as optimum cooking time (AACC 2011).

The cooking weight index (CWI) of pasta was calculated by dividing the weight of pasta after cooking by the weight of uncooked pasta as a quotient weight of cooked pasta after cooking to optimum cooking time. Measurements were made in triplicate for each sample (Biernacka et al. 2017).

Cooking loss (CL) as the amount of pasta components leached into cooking water was evaluated according to AACC 66-50.01 method (AACC 2011). Cooking loss was measured by evaporating the cooking water after OCT to dryness in an air oven in triplicate.

ZwickRoell BDO-FB0.5TH (Zwick GmbH \& Co., Ulm, Germany) universal testing machine was used for evaluation of dry and cooked pasta hardness as the maximum force peak during cutting test. Cutting force $(\mathrm{N})$ was measured with Warner-Bratzler knife double-face truncated at an angle $45^{\circ}$ with $3 \mathrm{~mm}$ thick and $60 \mathrm{~mm}$ long. The head speed during the tests was set at $500 \mathrm{~mm} / \mathrm{min}$. A force-time curves were achieved and analysed with testXpertII $^{\circledR} \mathrm{v} 3.3$ from data of 10 replications (Wójtowicz and Mościcki 2014).

\section{Color profile}

Color profile of pasta was measured for dry and cooked pasta using Supercolor HP 2132 colorimeter (Braive Instruments, Oupeye, Belgium) in CIE-Lab scale. The measurements determined chromatic coordinates of $L^{*}, a^{*}$ and $b^{*}$. A coordinate $L^{*}$ described the brightness in the range from 0 to 100 (black to white). A coordinate $a^{*}$ described the redness-greenness balance in-minus for green color to in-plus for red color. A coordinate $b^{*}$ described the yellowness-blueness balance in-minus for blue to in-plus for yellow (Wójtowicz et al. 2017). For each sample measurements were made in five replications.

\section{Sensory evaluation}

Sensory characteristic of dry and cooked pasta was evaluated according to Bouasla et al. (2016) and Rekha et al. (2013). The assessment was conducted on a 9-point hedonic scale with score 1 for dislike extremely, 5 for nor like nor dislike, to 9 for like extremely, the evolution above 5 was noted as acceptable (Boroski et al. 2011). The 
evaluation panel consisted fifteen persons (15 males, 30 females, aged 21-50 years) familiar with the definitions of sensory attributes of pasta. The dry and cooked pasta were served in amount of approximately $50 \mathrm{~g}$ on white platters. Cooked pasta was tested 5 min after cooking with OCT and rinsing with cold water. The samples were evaluated in a laboratory room with a natural sunlight. The dry pasta samples were assessed for appearance, color and aroma, and the cooked pasta evaluation involved appearance, color, aroma, taste and texture. For all samples the overall acceptability was determined as the average of the points received from the assessment of all the examined features. For dry pasta, as very good appearance was defined pasta with a specific appearance suitable for the type and shape of pasta without cracks or any spots. The perfect color and aroma of pasta should be specific to the raw materials used without foreign flavor. For cooked pasta, very good appearance was defined as smooth surface without sticks and roughness. Color for this type of pasta should be uniform and specific to the raw materials used. Aroma should not contain foreign flavor. Taste should be pleasant and characteristic for the ingredients used. Pasta with good texture should be uniform, soft, firm, compact, not adhesive and not too chewy.

\section{Statistical analysis}

Experimental results were mean $\pm \mathrm{SD}$ of multiple measurements. Analysis of variance was performed by ANOVA procedures (Statistica 13.1, StatSoft, Poland). Significant differences between means were determined by Tukey test with significance level of $\alpha=0.05$. Correlation matrix between the tested features have been prepared and correlations have been identified as significant above 0.600 value at $\alpha=0.05$.

\section{Results and discussion}

\section{Phenolics content in pasta}

Polyphenols are the most common antioxidants in a daily diet. Its' functional effect is attributed to the anti-inflammatory, antibacterial, antiviral and anticarcinogenic activity in human body as well as high antioxidant capacity, and thus beneficial to the human health. Nicoletti et al. (2015) reported the amount of total polyphenol content in various species of Cistus plant as GEA equivalent and they found 33.16, 32.51 and $40.51 \mathrm{mg} \mathrm{GAE} / \mathrm{g}$ in $C$. monspeliensis, $C$. villosus and C. libanotis, respectively. The amounts of phenolic compounds of dry $C$. incanus herb methanol extracts (ME) and phosphate buffer saline extracts (PBSE) were found at $301.9 \mathrm{mg} \mathrm{GAE} / \mathrm{g}$ d.w. and $457 \mathrm{mg} \mathrm{GAE} / \mathrm{g}$ d.w., respectively. Table 1 shows the content of phenolic compounds in methanol and phosphate buffered saline extracts present in dry pasta. The lowest amount of phenolic compounds (6.64 $\mathrm{mg} \mathrm{GEA} / \mathrm{g}$ d.w.) was found in the ME of wheat pasta without additive. Over twice as more of polyphenols were found in the ME sample supplemented with $5 \%$ of $C$. incanus. The increased amount of phenolic compounds in ME varied from $8.45 \mathrm{mg}$ GEA/g d.w. for pasta with $1 \%$ of additive up to $15.27 \mathrm{mg}$ GEA/g d.w. for pasta supplemented with $5 \%$ of additive. The content of total phenolic compounds found in PBSE samples showed better extractability of these components from dry pasta than in ME (Table 1). The highest amount of phenolic compounds was identified in pasta with $5 \%$ of the $C$. incanus content, the phenolic compounds content reached $18.28 \mathrm{mg} \mathrm{GEA} / \mathrm{g}$ d.w. The least amount of phenolic compounds, $8.71 \mathrm{mg} \mathrm{GEA} / \mathrm{g}$ d.w., was found in ME of pasta sample without additives. The use of dried Cistus plant as an additive in the range up to 5\% resulted in an increased phenolics content of about $229.97 \%$ if ME was used and $209.87 \%$ if PBSE was applied for extraction compared to control sample. The results of phenolic profile and antioxidant capacity of hydromethanolic and aqueous extracts of commercial C. incanus products presented by Viapiana et al. (2017) revealed that aqueous extracts of $C$. incanus are richer in phenolic compounds and have stronger antioxidant activities than hydromethanolic extracts. Moreover, they found more effective antibacterial activities of aqueous extracts against Gram-positive than Gram-negative bacteria. Pasta products fortified with 1-5\% of carob flour showed the increased amount of phenolic compounds from $5.27 \mathrm{mg} / \mathrm{g}$ d.w. for pasta with $1 \%$ up to $12.12 \mathrm{mg} / \mathrm{g} \mathrm{d}$.w. if $5 \%$ of carob flour was applied (Sęczyk et al. 2016). Comparying these data with presented results it can be stated that the addition of $C$. incanus is more beneficial to improve the nutritional quality of wheat pasta than carob flour. Bouasla et al. (2016) reported increased level of total phenolics content in precooked gluten-free rice pasta supplemented with selected legumes: yellow pea, lentil and chick pea, added up to $30 \%$. Chakraborty et al. (2016) noticed that total phenolics content of the pasta and the extruded snacks enriched with a mixture of coriander leaves, curry leaves and fenugreek leaves increased with increrasing the amount of additives. The level of the additives reported in the literature is varying in wide range, but the possibility to apply dried herbs is limited because of its specific intensive aroma and herbal taste. In Table 2 it have been identified significant correlations between phenolics content and antioxidant activity of supplemented pasta. TPC ME was highly positively correlated with the amount of $C$. incanus (0.98) and with TPC PBSE (0.96), and negatively correlated with the DPPH ME and DPPH PBSE ( -0.91 and -0.94 , respectively). On the other 
Table 1 The content of polyphenols (mg GAE/g d.w.) in methanol extract (ME) and buffer extract (BE) of dry pasta depend on Cistus incanus participation

\begin{tabular}{|c|c|c|}
\hline Addition of Cistus incanus (\%) & TPC in ME (mg GAE/g) & $\mathrm{TPC}$ in $\mathrm{BE}(\mathrm{mg} \mathrm{GAE} / \mathrm{g})$ \\
\hline 0 & $6.64 \pm 0.26^{\mathrm{c}}$ & $8.71 \pm 0.61^{\mathrm{d}}$ \\
\hline 1 & $8.45 \pm 0.68^{\mathrm{ac}}$ & $11.04 \pm 0.02^{\mathrm{a}}$ \\
\hline 2 & $10.34 \pm 0.22^{\mathrm{ab}}$ & $12.52 \pm 0.28^{\mathrm{a}}$ \\
\hline 3 & $11.13 \pm 0.07^{\mathrm{ab}}$ & $15.73 \pm 0.28^{\mathrm{b}}$ \\
\hline 4 & $12.89 \pm 0.85^{\mathrm{bd}}$ & $17.15 \pm 0.33^{\mathrm{bc}}$ \\
\hline 5 & $15.27 \pm 0.59^{\mathrm{d}}$ & $18.28 \pm 0.13^{\mathrm{c}}$ \\
\hline
\end{tabular}

hand, TPC PBSE was highly positively correlated with $C$. incanus level (0.99) and negatively correlated with DPPH ME and DPPH PBSE ( -0.98 and -0.96 , respectively), with FRAP ME and FRAP PBSE $(-0.91$ and -0.93 , respectively) as well as with aroma of dry pasta $(-0.92)$.

\section{Antioxidant activity of pasta tested with DPPH, ABTS and FRAP}

DPPH is an example of a long-lived nitrogen radical. Many antioxidants react very slowly on this radical (Gorkem 2016). Determinant of antioxidant activity by DPPH method is the most common method (Boroski et al. 2011). The scavenging capacity of DPPH free radical for $C$. incanus dry herb was noted at the level of $8.04 \mathrm{mg} \mathrm{d.w.} / \mathrm{mL}$ of $\mathrm{EC}_{50}$ in ME extracts and of $2.6 \mathrm{mg} \mathrm{d.w.} / \mathrm{mL}$ in PBSE extracts. Figure 1 shows the distribution of the activity of compounds contained in ME and PBSE extracts of pasta supplemented with $C$. incanus leaves. Higher values of these indicators mean lower antioxidant activity. The lowest scavenging capacity of the free radical DPPH was noted in wheat pasta samples with value of $96.54 \mathrm{mg} \mathrm{d.w./}$ $\mathrm{mL}$ of $\mathrm{EC}_{50}$ in ME extracts. The highest capacity, for both used extractants, was evaluated in extracts of pasta enriched with $5 \%$ of Cistus leaves and it was over double more active than in samples without additive. The remaining $\mathrm{EC}_{50}$ values in $\mathrm{ME}$ ranged from $41.08 \mathrm{mg}$ d.w. $/ \mathrm{mL}$ (5\% of additive) to $87.21 \mathrm{mg}$ d.w./mL (1\% of additive). The largest differences in the increase in antioxidant activity have been noted between samples supplemented with 2 and $3 \%$ of $C$. incanus leaves. The ability to scavenge the free $\mathrm{DPPH}$ radicals in the tested PBSE, expressed as $\mathrm{EC}_{50}$ index, ranged from 75.00 to $316.22 \mathrm{mg} \mathrm{d.w.} / \mathrm{mL}$. The scavenging activity of pasta PBSE increased with the addition of dried Cistus leaves amount, the most significant increase of $40 \%$ was observed between the samples with 3 and $4 \%$ of additive applied. Highly positive correlations (0.98) have been observed between antioxidant activity DPPH ME and DPPH PBSE (Table 2). The antioxidant activity of DPPH ME and PBSE in the same time was highly negatively correlated with the C.incanus amount (both - 0.98) and positively correlated with the FRAP PBSE (0.93 and 0.90, respectively) as well as with aroma of dry pasta (0.94 and 0.92, respectively). Marcinčák et al. (2008) found that the highest antioxidant capacity using the synthetic DPPH radical was characterized by methanol extracts of oregano (95.20\%) and lemon balm (91.20\%). Moreover, Chakraborty et al. (2016) reported that pasta enriched with a mix of leaves (coriander, curry, fenugreek) characterized greater ability to scavenge free radicals than extruded snacks, so supplementation of cold-pressed pasta could be an efficient way to improve nutritional quality according to the antioxidant activity of final products. But it was also found a small effect of HTST extrusion-cooking treatment on antioxidant activity of extrudates supplemented with chamomile, echinacea or elderberry fruits or flowers (Oniszczuk et al. 2015b, c, 2016a, b, respectively).

The results of the antiradical activity of free radicals against ABTS of compounds contained in ME and PBSE extracts, shown in Fig. 1, confirmed previous tendencies observed for DPPH. The antiradical activity of $C$. incanus dry herb against ABTS was characterized in ME and PBES extracts with the $\mathrm{EC}_{50}$ at 14.2 and $10.8 \mathrm{mg}$ d.w./mL, respectively. The lowest antiradical activity was characterized by extracts of wheat pasta made without the addition of a plant with $\mathrm{E}_{50}$ at 214.73 and $59.65 \mathrm{mg} \mathrm{d.w./}$ $\mathrm{mL}$ in methanol and buffer extracts, respectively. Enrichment of pasta with $1 \%$ addition of dried Cistus leaves resulted in a $62 \%$ increase in activity against ABTS in ME and $32 \%$ in PBSE. The antiradical activity increased by over $87 \%$ in $\mathrm{ME}$ and $52 \%$ in PBSE when tested material contained $5 \%$ of additive. The Table 2 shows that between antioxidant activity of ABTS ME and ABTS PBSE was observed highly positive correlation (0.98). The antioxidant activity of ABTS ME and PBSE were highly positively correlated with the FRAP ME (0.98 and 0.99, respectively) and FRAP PBSE (0.93 and 0.96, respectively). However, the only antioxidant activity of ABTS 

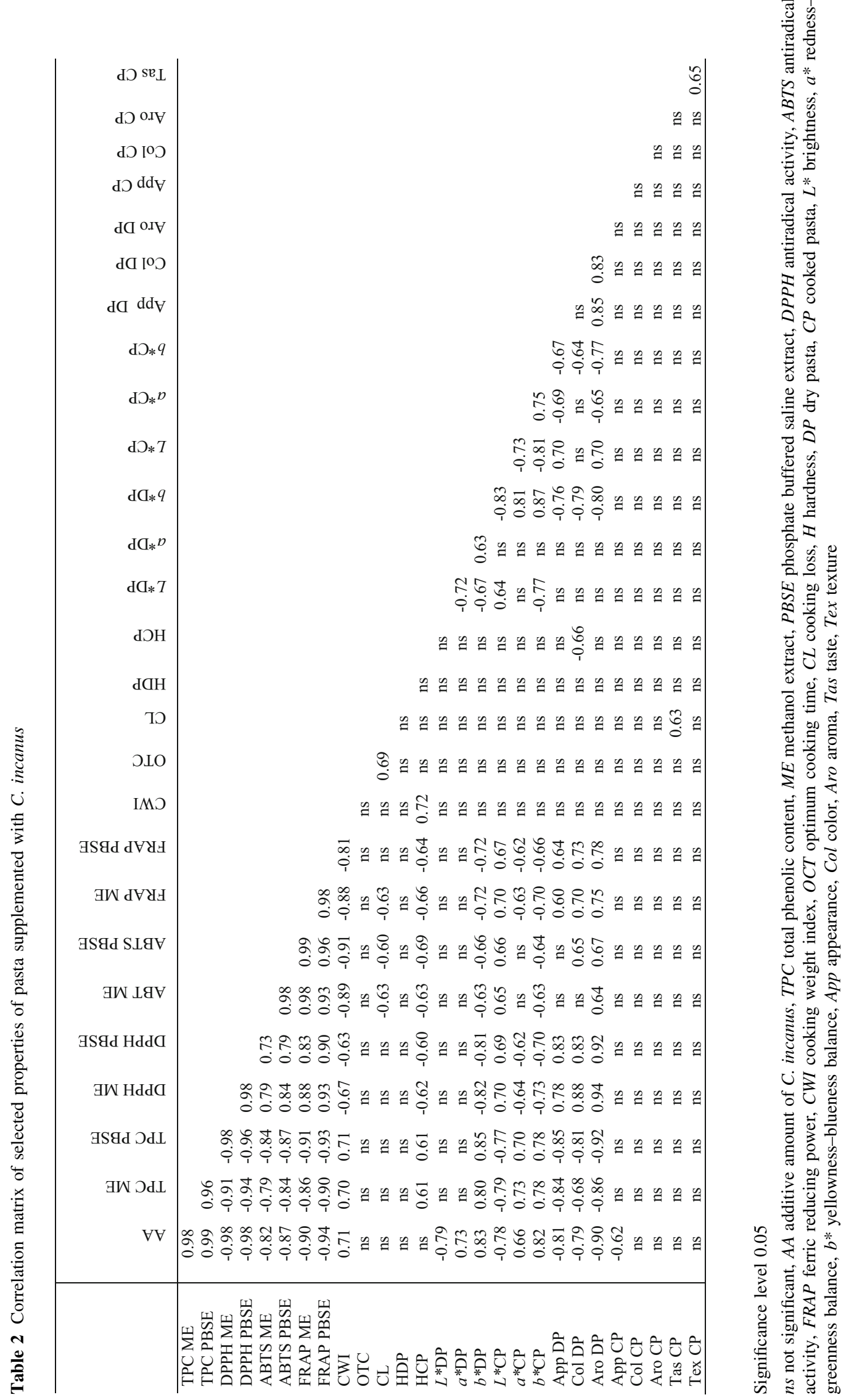


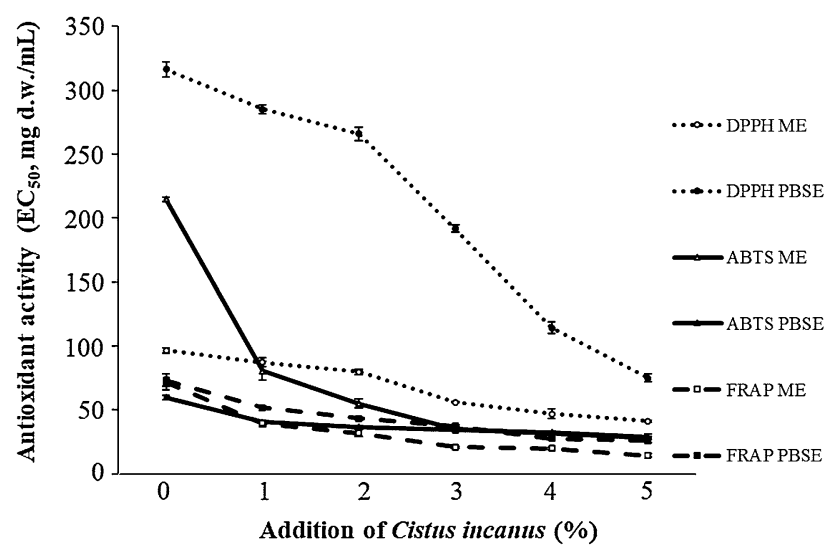

Fig. 1 Antioxidant activity of compounds contained in methanol extracts (ME) and phosphate buffered saline extracts (PBSE) of dry wheat pasta depend on Cistus incanus participation tested with DPPH, ABTS and FRAP method

PBSE was highly negatively correlated with the cooking weight index $(-0.91)$. The results obtained by Sant'Anna et al. (2014) suggest that the scavenging capability of the ABTS free radicals of pasta supplemented with grape marc powder is related to the presence of anthocyanins in the final product. While Seczyk et al. (2016) observed that for wheat pasta fortified with carob flour (1-5\%) inreased antiradical activity from about twofolds to 18 -folds.

The results of ferric-reducing power of ME and PBSE of tested pasta are presented in Fig. 1. The increase in reduction capacity against FRAP was related to the increasing amount of $C$. incanus in the composition (Table 2). ME of wheat pasta characterized the reduced capacity against FRAP expressed as $\mathrm{EC}_{50}(71.80 \mathrm{mg}$ d.w./ $\mathrm{mL}$ ). For ME and PBSE extracts of dry C. incanus herb the reduction capacity of FRAP was noted at $0.62 \mathrm{mg} \mathrm{d} . \mathrm{w} . / \mathrm{mL}$ and $0.42 \mathrm{mg}$ d.w./mL, respecively. The best ability to reduce ferric ions by the compounds contained in the $\mathrm{ME}$ of enriched pasta was found in samples with a $5 \%$ of plant leaves, it has reached the $\mathrm{EC}_{50}$ value of $14.32 \mathrm{mg} \mathrm{d.w.} / \mathrm{mL}$. According Biernacka et al. (2017) the ferric-reducing power is increasing with increased amount of carob fiber in the wheat pasta. The FRAP abilities to reduce the compounds contained in the PBSE of the tested pasta were found in a range of $\mathrm{EC}_{50}$ from $72.95 \mathrm{mg} \mathrm{d} . \mathrm{w} . / \mathrm{mL}$ to wheat pasta up to $25.65 \mathrm{mg} \mathrm{d.w./mL}$ for pasta with $5 \%$ of additive. So, the increase in ferric-reducing power was significant $(20 \%$ in $\mathrm{ME}$ and $35 \%$ in PBES). However, not dependently the extraction procedure, the highest reducing capacity was observed in the pasta with the largest amount of $C$. incanus in the recipe. Nicoletti et al. (2015) reported the results of antioxidant activity against DPPH for extracts from various species of Cistus plant. They found significant differences between various types of tested plants, both as $\mathrm{DPPH}$ antiradical activity as well as reducing power $\mathrm{EC}_{50}$, in a range of 3-28 $\mu \mathrm{g} / \mathrm{mL}$ and $142-28 \mu \mathrm{g} / \mathrm{mL}$, respectively. Loizzo et al. (2013) tested antioxidant properties as radical scavenging ability and ferric reducing ability of five species of Cistus essential oils with DPPH, ABTS and FRAP tests, respectively. They found DPPH antiradical activity ranged from 499.9 to $991.9 \mu \mathrm{g} / \mathrm{mL}$, ABTS ranged from 272.5 to $395.1 \mu \mathrm{g} / \mathrm{mL}$ and FRAP ability ranged from 0.4 to $19.4 \mu \mathrm{M} \mathrm{Fe} / \mathrm{g}$. Highly positive correlations were observed between reduction capacity against FRAP of ME and PBSE extracts and antioxidant activity measured with other methods (Table 2). Additionally, highly negative correlations were noted between the additive amount and reduction capacity against FRAP ME and PBSE ( -0.90 and - 0.94, respectively). Significant correlations have been found also with color determinants of cooked pasta as well as with sensory properties of dry products. Wheat pasta fortified with carob flour by supplementation of $1-5 \%$ had an effect on increased ability to reduce $\mathrm{Fe}_{3}{ }^{+}$ions from about 100-300\% (Sęczyk et al. 2016). Cárdenas-Hernández et al. (2016) noted that pasta exhibited higher phenols content than pure pasta and reduced antioxidant power once enriched with amaranth addition, especially the leaves.

\section{Cooking quality of pasta}

Results of cooking quality of pasta enriched with $C$. incanus dried leaves are presented in Table 3. The optimum cooking time (OCT) evaluated for wheat pasta and products enriched with $C$. incanus dried leaves was $12.5 \mathrm{~min}$ and differences between tested samples were not significantly different $( \pm 0.5 \mathrm{~min})$, probably due to the small amount of additive used in the experiment. The cooking weight index (CWI) was found on the level of 3.28 for the wheat pasta without additive. Application of $C$. incanus dried leaves as an additive influenced variously on the cooking weight of supplemented pasta. Obtained values ranged from 3.20 when tested pasta with $1 \%$ of $C$. incanus addition to 3.36 for pasta supplemented with $3 \%$ of dried leaves added. Higher amount of additive lowered CWI because of disruption of continuous gluten matrix by the addition of herbal component with high fiber level. Nevertheless, observed differences in CWI were not significantly different. In the case of wheat pasta, fortification with carrot and oregano leaves also had no significant effect on the technological quality of the final product (Boroski et al. 2011). Cooking weight is more dependent on the preparation time as reported by Dziki and Laskowski (2005) during evaluation of spaghetti-type pasta produced from semolina, they observed the cooking weight index increased significantly from 2.7 for OCT to 3.3 during overcooking. Biernacka et al. (2018) reported the weight increase index of pasta from 2.62 to 3.00 if various 
wheat pasta were tested, whereas the cooking loss varied from 4.76 to $6.55 \%$. They found significant and negative correlation was found between protein content and CL. In our study cooking loss of pasta supplemented with $C$. incanus not exceed $10 \%$ what is indicating pasta with high quality. Significant positive correlation of CWI was observed with hardness of cooked pasta (0.72, Table 2). Moreover, CL was significantly positively correlated with optimum cookin time and with taste of cooked pasta (0.69 and 0.63 , respectively). As shown in Table 3 increased amount of additive in the recipe resulted in higher cooking losses from $5.7 \%$ for control wheat pasta up to $9.8 \%$ for products supplemented with 5\% of Cistus herb. Addition of dry herbs lowered the total amount of proteins and disturbed the continuous gluten matrix by the addition of high-fiber dry plant fractions. It is well known that lower protein content results in a weaker protein matrix and higher CL so by increased addition of Cistus leaves the total protein content decreased (Biernacka et al. 2018). Boroski et al. (2011) found the highest soluble losses during cooking for pasta supplemented with $20 \%$ of oregano and carrot leaf meal what may be related to structural changes in the gluten chain caused by proteins in the leaf meal.

Hardness of pasta was tested for dry and cooked products. Pasta cutting force as an indirect indicator of pasta hardness is a frequently determined for single or multiple pasta treads (Bouasla et al. 2016; Gull et al. 2015). Dry pasta hardness, expressed as cutting force, did not differ significantly, except of sample with the highest amount of $C$. incanus dry leaves what showed low cutting force (Table 3) as the result of weak inside structure of dry pasta and tendency to crush very easily. Hardness of cooked pasta ranged from $0.26 \mathrm{~N}$ for control wheat pasta up to $0.41 \mathrm{~N}$ for samples with 5\% of dry Cistus added. High content of fiber in pasta recipe caused higher hardness after OTC. This could be the result of the competition for the water molecules between starch, proteins and fiber and different hydration levels of the constituents, which in turn can affect the strength of gluten network formed (La Gatta et al. 2017). Biernacka et al. (2018) found cooked pasta hardness ranged from 0.52 to $1.65 \mathrm{~N}$ for various types of commercial wheat pasta products based on common and durum wheat flour. Table 2 shows that hardness of cooked pasta was significantly negatively correlated with only sensory color of dry pasta $(-0.66)$.

\section{Color determination of pasta products}

According to Italians, who are the leaders in Europe in the consumption of pasta, good quality pasta should have the yellow color which is desirable by consumers (Piwińska et al. 2016). Moreover, color of the product is the first evaluated parameter affecting on buying decisions. In the case of tested pasta fortified with $C$. incanus evaluation of color discriminants for dry and cooked pasta occurred with the coordinate system $L^{*}, a^{*}$ and $b^{*}$ (Table 4 ). The highest brightness (value $L^{*}=74.58$ ) was observed for dry pasta without additives. For dry pasta the lowest value of this parameter 61.06 was noted for products fortified with 5\% of $C$. incanus in the composition. There was observed significant differences between samples, especially comparing to control sample. Addition of 1-3\% of dried Cistus leaves did not affected significantly on dry pasta brightness. While determining the brightness of cooked pasta the highest value of the $L^{*}$ coordinate was noted in wheat pasta without the addition of $C$. incanus with the value of 52.22 . In relation to pasta before cooking the decrease in brightness occurred by approx. 30\%. The lowest value of $L^{*}$ coordinate for cooked pasta was determined for pasta with 5\% addition of dried Cistus leaves (40.02). Increasing the amount of Cistus additive caused significant reduction of cooked pasta brightness because of the brown-red shade of dry herb. There was also observed significant decrease in supplemented products brightness after cooking compared to dry pasta. The decrease in brightness of pasta could be

Table 3 Results of cooking characteristics and texture of dry and cooked wheat pasta depend on Cistus incanus participation

\begin{tabular}{|c|c|c|c|c|c|}
\hline \multirow[t]{2}{*}{ Addition of Cistus incanus (\%) } & \multirow[t]{2}{*}{ CWI (-) } & \multirow[t]{2}{*}{ OCT (min) } & \multirow[t]{2}{*}{ CL (\%) } & \multicolumn{2}{|l|}{ Hardness (N) } \\
\hline & & & & Dry pasta & Cooked pasta \\
\hline 0 & $3.29 \pm 0.01^{\mathrm{b}}$ & $12.5 \pm 0.5^{\mathrm{a}}$ & $5.7 \pm 0.002^{\mathrm{b}}$ & $4.68 \pm 2.89^{\mathrm{a}}$ & $0.26 \pm 0.04^{\mathrm{a}}$ \\
\hline 1 & $4.36 \pm 0.13^{\mathrm{a}}$ & $12.0 \pm 0.5^{\mathrm{a}}$ & $6.8 \pm 0.001^{\mathrm{ab}}$ & $4.81 \pm 1.15^{\mathrm{a}}$ & $0.29 \pm 0.04^{\mathrm{ab}}$ \\
\hline 2 & $4.12 \pm 0.11^{\mathrm{a}}$ & $14.5 \pm 0.5^{\mathrm{a}}$ & $6.7 \pm 0.001^{\mathrm{ab}}$ & $5.00 \pm 1.69^{\mathrm{a}}$ & $0.38 \pm 0.10^{\mathrm{ab}}$ \\
\hline 3 & $4.33 \pm 0.04^{\mathrm{a}}$ & $14.5 \pm 0.5^{\mathrm{a}}$ & $8.1 \pm 0.003^{\mathrm{a}}$ & $5.16 \pm 1.92^{\mathrm{a}}$ & $0.34 \pm 0.07^{\mathrm{ab}}$ \\
\hline 4 & $4.19 \pm 0.13^{\mathrm{a}}$ & $12.0 \pm 0.1^{\mathrm{a}}$ & $7.8 \pm 0.001^{\mathrm{a}}$ & $4.33 \pm 1.62^{\mathrm{a}}$ & $0.36 \pm 0.12^{\mathrm{ab}}$ \\
\hline 5 & $4.56 \pm 0.09^{\mathrm{a}}$ & $12.0 \pm .01^{\mathrm{a}}$ & $9.8 \pm 0.005^{\mathrm{c}}$ & $2.79 \pm 1.16^{\mathrm{b}}$ & $0.41 \pm 0.08^{\mathrm{ab}}$ \\
\hline
\end{tabular}

$\mathrm{n}=3$; mean $\pm \mathrm{SD}$

$C W I$ cooking weight index, $O C T$ optimum cooking time, $C L$ cooking loss

${ }^{\mathrm{a}-\mathrm{c}}$ Means followed by the same letter within a column indicate no significant difference $(p<0.05)$ in Tukey test 
the result of non-enzymatic browning, Maillard reactions occurred at very high temperature of drying or additives applied (Piwińska et al. 2016). Significant positive correlations (Table 2) were observed between value $L^{*}$ of dry pasta and value $L^{*}$ of cooked pasta (0.64). Furthermore, value $L^{*}$ of dry pasta was significantly negatively correlated with $a^{*}$ and $b^{*}$ value of dry pasta $(-0.72$ and -0.67 , respectively). Also, the $L^{*}$ value of cooked pasta was significantly negatively correlated with additive amount, total phenolic content and $b^{*}$ of dry pasta whereas the positive correlations have been found between lightness of cooked pasta and its antioxidant activity (Table 2). Quite opposite tendencies were observed for $b^{*}$ of cooked pasta. The chromatic coordinate $a^{*}$, indicating rednessgreenness balance reached in-plus values what is associated with the slight brown-red tint of dry pasta. The highest $a^{*}$ value was determined for dry and cooked pasta with addition of $1 \%$ of $C$. incanus and was respectively 3.33 and 4.38 (Table 4). In dry pasta a small increase of redness intensity was observed according to increased level of dry Cistus leaves because of its brown-red shade after drying. Not significant differences were observed in $a^{*}$ coordinate values for cooked pasta, slide increase in redness was noted for samples with increased dried herb addition. Small differences in pasta redness before and after cooking showed similar red tint of both dry and cooked pasta. According to Biernacka et al. (2017) the effect of the color characteristic depends on the raw materials, processing parameters and especially drying conditions. The authors observed that addition of carob fiber to common wheat pasta decreased the value of the $a^{*}$ coordinate from 17.3 to 2.7. Uncooked pasta with spinach showed intensive green color as seen by negative $a^{*}$ value that indicates green shade opposite to carrot, beetroot and tomato supplemented pasta (Rekha et al. 2013). They reported the color of cooked samples was slightly lesser as compared to dry ones and leaching of color components during pasta cooking was negligible probably due to solubility in water carotenes and chlorophylls from vegetables. Significant positive correlation (0.63) was observed between value $a^{*}$ and $b^{*}$ of dry pasta. Color coordinate $a^{*}$ was positively correlated with additive amount and TPC whearas negative correlations have been found with antioxidant activity, especially by DPPH and FRAP radicals scavenging power (Table 5).

During the assessment of the $b^{*}$ coordinate (Table 4), the highest intensity of the yellow shade was determined for dry pasta with 5\% C. incanus content (17.66), while the smallest value, 10.52 , was determined during testing wheat pasta without the addition of $C$. incanus. For cooked pasta, the $b^{*}$ coordinate value assumed a maximum value of 14.95 during evaluating the color of the pasta with a $5 \% C$. incanus, while the lowest intensity of yellowness 6.66 was characterized by wheat pasta as control sample. The increase in $b^{*}$ values for dry pasta was $67 \%$ according to color of control sample, while after cooking increase in yellowness was more significant (124\%). Difference in yellowness between dry and cooked products was about 16-20\% for pasta with the same content of C. incanus, but for control pasta difference was more visible (37\%). Reduction in yellow color intensity of cooked pasta could be due to swelling of pasta and conversion of pigments resulting in decrease in yellowness during cooking, but all the tested pastas had good attractive color after cooking. $b^{*}$ value of dry pasta was positively correlated with amount of additive, TPC, $a^{*}$ and value $b^{*}$ of cooked pasta but negatively correlated with antioxidant activity for all the tested extracts, with $L^{*}$ of cooked pasta as well as with sensory characteristics of dry products (Table 2).

Table 4 Mean values of color coordinates $L^{*}, a^{*}$ and $b^{*}$ of pasta depend on Cistus incanus participation

\begin{tabular}{|c|c|c|c|c|c|c|}
\hline \multirow[t]{2}{*}{ Addition of Cistus incanus (\%) } & \multicolumn{3}{|l|}{ Dry pasta } & \multicolumn{3}{|l|}{ Cooked pasta } \\
\hline & $L^{*}$ & $a^{*}$ & $b^{*}$ & $L^{*}$ & $a^{*}$ & $b^{*}$ \\
\hline 0 & $74.58 \pm 2.79^{c}$ & $2.54 \pm 0.82^{\mathrm{a}}$ & $10.52 \pm 0.34^{\mathrm{d}}$ & $52.22 \pm 5.45^{\mathrm{c}}$ & $1.08 \pm 0.97^{\mathrm{b}}$ & $6.66 \pm 0.35^{\mathrm{c}}$ \\
\hline 1 & $69.24 \pm 1.47^{\mathrm{bc}}$ & $3.33 \pm 0.46^{\mathrm{a}}$ & $14.83 \pm 0.48^{\mathrm{a}}$ & $46.08 \pm 2.01^{\mathrm{b}}$ & $4.38 \pm 0.71^{\mathrm{a}}$ & $11.90 \pm 1.52^{\mathrm{a}}$ \\
\hline 2 & $68.45 \pm 1.67^{\mathrm{abc}}$ & $3.60 \pm 0.20^{\mathrm{ab}}$ & $15.32 \pm 1.16^{\mathrm{ab}}$ & $44.00 \pm 1.84^{\mathrm{ab}}$ & $3.40 \pm 1.09^{\mathrm{a}}$ & $12.84 \pm 1.01^{\mathrm{ab}}$ \\
\hline 3 & $68.12 \pm 1.33^{\mathrm{abc}}$ & $4.00 \pm 1.27^{\mathrm{ab}}$ & $16.05 \pm 0.21^{\mathrm{abc}}$ & $44.75 \pm 2.90^{\mathrm{ab}}$ & $4.08 \pm 0.89^{\mathrm{a}}$ & $13.88 \pm 1.72^{\mathrm{ab}}$ \\
\hline 4 & $62.12 \pm 4.33^{\mathrm{ab}}$ & $3.76 \pm 0.56^{\mathrm{ab}}$ & $16.68 \pm 0.63^{\mathrm{bc}}$ & $43.36 \pm 0.70^{\mathrm{ab}}$ & $4.75 \pm 0.21^{\mathrm{a}}$ & $14.43 \pm 0.29^{\mathrm{ab}}$ \\
\hline 5 & $61.06 \pm 5.03^{\mathrm{a}}$ & $5.12 \pm 0.45^{\mathrm{b}}$ & $17.66 \pm 1.14^{\mathrm{c}}$ & $40.02 \pm 3.27^{\mathrm{a}}$ & $5.24 \pm 1.52^{\mathrm{a}}$ & $14.95 \pm 1.13^{\mathrm{b}}$ \\
\hline
\end{tabular}

$\mathrm{n}=5$; mean $\pm \mathrm{SD}$

$L^{*}$ brightness, $a^{*}$ redness(+)-greenness(-) balance, $b^{*}$ yellowness(+)-blueness(-) balance

${ }^{\mathrm{a}-\mathrm{d}}$ Means followed by the same letter within a column indicate no significant difference $(p<0.05)$ in Tukey test 


\section{Sensory evaluation of pasta}

During the sensory evaluation of dry pasta (Table 5) the highest scores of the overall acceptability were noted for the control pasta and samples enriched with 1 and $2 \%$ of $C$. incanus added. With the increase of the amount of herbaceous additive, lower notes were observed for the color assessment, because of higher additive level visually resulted in the loss of the color uniformity. The increasing amount of the additive in the evaluation of raw pasta resulted in lowering the ratings for the external appearance. Most likely, this was due to the appearance of dark spots that resulted from the addition of $C$. incanus. The increase of $C$. incanus addition in pasta recipe also adversely affected the assessment of the aroma because of too intensive herbal flavor resulted in lowering the scores for the aroma of pasta with an additive content above 3\%. The overall quality counted as mean of all assessed features showed that the control pasta and products with 1 and $2 \%$ of the additive content received the score 7.5 , which constituted of $83.3 \%$ of the possible points. Pasta with $3 \% C$. incanus received approximately about $30 \%$ less points than the top ones. The pasta with the addition of 5\% of the herb supplement was rated the worst, receiving 4.3 points, which constituted $47.7 \%$ of total points to be awarded. Table 2 shows that appearance, color and aroma of dry pasta as well as appearance of cooked pasta were negatively correlated with additive amount. Assessment of cooked pasta sensory attributes showed the highest overall acceptability was found for pasta supplemented with $1 \%$ of C. incanus dry leaves. The pasta made with this recipe after cooking characterized the best appearance, color, taste and texture. When assessing the aroma, as compared to pasta with $1 \%$ of the additive, slightly higher scores were noted for pasta with $4 \%$ of $C$. incanus content. The lowest rated product was cooked pasta with $5 \%$ content of additive, the lowest scores for all sensory attributes were noted for this product. Significant positive correlation (0.65) was observed between the taste and texture of cooked pasta (Table 2). Whereas, as reported by La Gatta et al. (2017), supplementation of pasta with high-fiber bran fractions may cause a weakening of the gluten protein network and may have a detrimental effect on its cooking and sensory quality. So the level of fibrous additives for pasta supplementation must combine nutritional properties, proper cooking quality and sensory attractiveness. Supplementation of the health ingredients should have no effect on the palatability as well as the consumer preference. Apart from the additional health benefits it offers, it should be rather delicious as well (Krishnan and Prabhasankar 2012). Taking all these into account it can be stated that pasta with maximum level of $3 \%$ of $C$. incanus addition is still

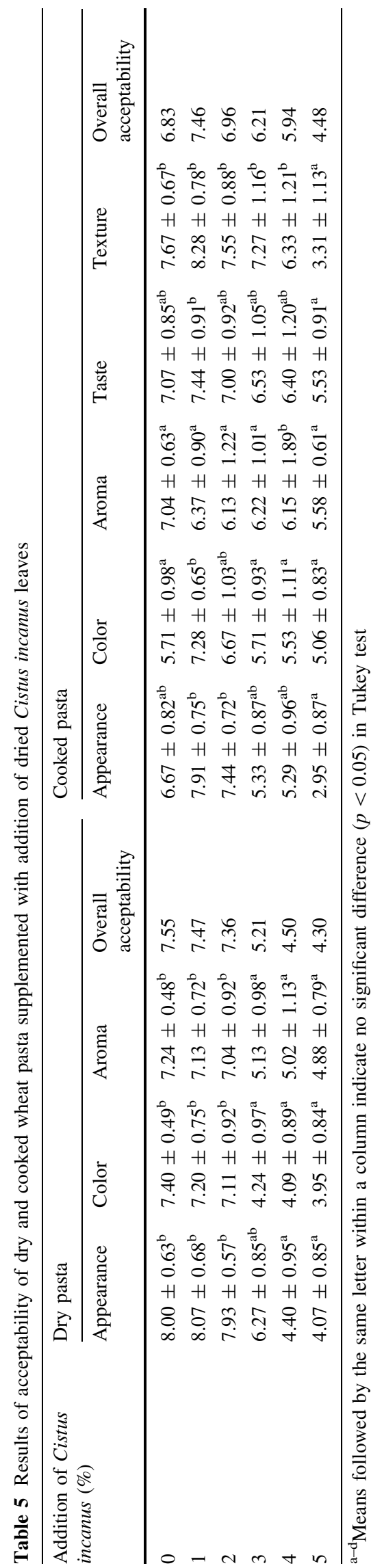


acceptable as well as presents improved nutritional characteristics.

\section{Conclusion}

Enrichment of common wheat pasta with the addition of $C$. incanus resulted in increasing the total phenolics content and also contributed in increasing the antioxidant activity of supplemented pasta. The content of total phenolic compounds found in enriched pasta extracted with BE showed better extractability of these components from dry pasta than in ME. The highest radical scavenging capacity against DPPH, for both used extractants, was evaluated in extracts of pasta enriched with $5 \%$ of Cistus leaves and over double more activity was noted than in samples without additives. The best ability to reduce ferric ions by the compounds contained in the ME of enriched pasta was found for samples with a $5 \%$ of plant leaves. The introduction of $C$. incanus to the pasta dough composition resulted in a slight increase in the cooking weight of pasta. The highest value of this indicator was obtained when testing pasta with $3 \%$ of additive. Increased addition of dry Cistus herb caused higher cooking loss and increased hardness of cooked pasta. The increasing addition of $C$. incanus had insignificant effect on the $a^{*}$ color coordinate of supplemented pasta, the only slight decrease of brightness and significant increase of yellowness were observed if the amount of additive raised. After cooking supplemented pasta was more darker and less yellow in color. On the base of the sensory evaluation it is recommended fortification of common wheat pasta with maximum $3 \%$ of $C$. incanus due to overall acceptability notes. This additive due to its high phenolics content and antioxidant activity as well as proper quality characteristics have a strong potential to be implemented in practice to produce supplemented pasta. It would be interesting for Authors to find more applications for $C$. incanus herb in food industry and some research will be continued in this field.

Acknowledgements The results of preliminary tests of pasta supplemented with Cistus incanus have been presented at the 11th World Congress on Polyphenols Applications in Vienna, Austria, 20-21 June 2017.

\section{Compliance with ethical standards}

Conflict of interest The authors declare that they have no conflict of interest.

Open Access This article is distributed under the terms of the Creative Commons Attribution 4.0 International License (http://crea tivecommons.org/licenses/by/4.0/), which permits unrestricted use, distribution, and reproduction in any medium, provided you give appropriate credit to the original author(s) and the source, provide a link to the Creative Commons license, and indicate if changes were made.

\section{References}

AACC International (2011) Approved methods of analysis, 11th edn. American Association of Cereal Chemistry, Saint Paul. http:// methods.aaccnet.org/about.aspx. Accessed 1 Sept 2018

Biernacka B, Dziki D, Gawlik-Dziki U, Różyło R, Siastała M (2017) Physical, sensorial, and antioxidant properties of common wheat pasta enriched with carob fiber. LWT Food Sci Technol 77:186-192. https://doi.org/10.1016/j.lwt.2016.11.042

Biernacka B, Dziki D, Różyło R, Wójcik M, Miś A, Romankiewicz D, Krzysiak Z (2018) Relationship between the properties of raw and cooked spaghetti-new indices for pasta quality evaluation. Int Agrophys 32(2):217-223. https://doi.org/10.1515/intag-20170012

Boroski M, De Aguiar AC, Schuelter Boeing J, Rotta EM, Leite Wibby C, Bonafé EG, De Souza NE, Visentainer JV (2011) Enhancement of pasta antioxidant activity with oregano and carrot leaf. Food Chem 125(2):696-700. https://doi.org/10.1016/ j.foodchem.2010.09.068

Bouasla A, Wójtowicz A, Zidoune MN, Olech M, Nowak R, Mitrus M, Oniszczuk A (2016) Gluten-free precooked rice-yellow pea pasta: effect of extrusion-cooking conditions on phenolic acids composition, selected properties and microstructure. J Food Sci 81(5):1070-1079. https://doi.org/10.1111/1750-3841.13287

Cárdenas-Hernández A, Beta T, Loarca-Piña G, Castaño-Tostado E, Nieto-Barrera JO, Mendoza S (2016) Improved functional properties of pasta: enrichment with amaranth seed flour and dried amaranth leave. J Cereal Sci 72:84-90. https://doi.org/10. 1016/j.jcs.2016.09.014

Chakraborty P, Bhattacharya A, Bhattacharyya DK, Bandyopadhyay NR, Ghosh M (2016) Studies of nutrient rich edible leaf blend and its incorporation in extruded food and pasta products. Mater Today Proc 3(10):3473-3483. https://doi.org/10.1016/j.matpr. 2016.10.030

Demetzos C, Katerinopoulos H, Kouvarakis A, Stratigakis N, Loukis A, Ekonomakis C, Spiliotis V, Tsaknis J (1997) Composition and antimicrobial activity of the essential oil of Cistus creticus subsp. eriocephalus. Planta Med 63(5):477-479. https://doi.org/10. 1055/s-2006-957742

Dziki D, Laskowski J (2005) Evaluation of the cooking quality of spaghetti. Pol J Food Nutr Sci 14(55):153-158

Gorkem Y (2016) Antioxidant capacity of a Turkish traditional alcoholic drink, Raki. Pol J Food Nutr Sci 66(3):167-171. https://doi.org/10.1515/pjfns-2015-0036

Gull A, Prasad K, Kumar P (2015) Effect of millet flours and carrot pomace on cooking qualities, color and texture of developed pasta. LWT Food Sci Technol 63(1):470-474. https://doi.org/10. 1016/j.lwt.2015.03.008

Harlina PW, Ma M, Shahzad R, Gouda MM, Qiu N (2018) Effect of clove extract on lipid oxidation, antioxidant activity, volatile compounds and fatty acid composition of salted duck eggs. J Food Sci Technol 55(12):4719-4734. https://doi.org/10.1007/ s13197-018-3367-8

Krishnan M, Prabhasankar P (2012) Health based pasta: redefining the concept of the next generation convenience food. Crit Rev Food Sci 52(1):9-20. https://doi.org/10.1080/10408398.2010. 486909

La Gatta B, Rutigliano M, Padalino L, Conte A, Del Nobile MA, Di Luccia A (2017) The role of hydration on the cooking quality of bran-enriched pasta. LWT Food Sci Technol 84:489-496. https://doi.org/10.1016/j.1wt.2017.06.013 
Loizzo MR, Jemia MB, Senatore F, Bruno M, Menichini F, Tundis R (2013) Chemistry and functional properties in prevention of neurodegenerative disorders of five Cistus species essential oils. Food Chem Toxicol 59:586-594. https://doi.org/10.1016/j.fct. 2013.06.040

Marcinčák S, Cabadaj R, Popelka P, Šoltýsová L (2008) Antioxidative effect of oregano supplemented to broilers on oxidative stability of poultry meat. Slov Vet Res 45(2):61-66

Móricz Á, Szeremeta D, Knaś M, Długosz E, Ott P, Kowalska T, Sajewicz M (2018) Antibacterial potential of the Cistus incanus L. phenolics as studied with use of thin-layer chromatography combined with direct bioautography and in situ hydrolysis. J Chromatogr A 1534:170-178. https://doi.org/10.1016/j. chroma.2017.12.056

Nicoletti M, Toniolo C, Venditti A, Bruno M, Ben Jemia M (2015) Antioxidant activity and chemical composition of three Tunisian Cistus: Cistus monspeliensis, Cistus villosus and Cistus libanotis. Nat Prod Res 29(3):223-230. https://doi.org/10.1080/14786419. 2014.947486

Oniszczuk A, Oniszczuk T, Wójtowicz A, Wojtunik K, Kwaśniewska A, Waksmundzka-Hajnos M (2015a) Radical scavenging activity of extruded corn gruels with addition of linden inflorescence. Open Chem 13(1):1101-1107. https://doi.org/10.1515/chem2015-0118

Oniszczuk A, Wójtowicz A, Oniszczuk T, Olech M, Nowak R, Wojtunik K, Klimek M, Krawczyk W, Hajnos M (2015b) Extruded corn gruels containing linden flowers: quantitation of phenolic compounds and selected quality characteristics. Open Chem 13(1):1209-1217. https://doi.org/10.1515/chem-20150138

Oniszczuk A, Wojtunik K, Oniszczuk T, Wójtowicz A, Mościcki L, Waksmundzka-Hajnos M (2015c) Radical scavenging activity of instant grits with addition of chamomile flowers determined by TLC-DPPH test and by spectrophotometric method. J Liq Chromatogr RT 38(11):1142-1146. https://doi.org/10.1080/ 10826076.2015.1028294

Oniszczuk A, Olech M, Oniszczuk T, Wojtunik K, Wójtowicz A (2016a) Extraction methods, LC-ESI-MS/MS analysis of phenolic compounds and antiradical properties of functional food enriched with elderberry flowers or fruits. Arab J Chem. https:// doi.org/10.1016/j.arabjc.2016.09.003

Oniszczuk T, Oniszczuk A, Gondek E, Guz L, Puk K, Kocira A, Kusz A, Kasprzak K, Wójtowicz A (2016b) Active polyphenolic compounds, nutrients contents and antioxidant capacity of extruded fish feed containing purple coneflower (Echinacea purpurea). Saudi J Biol Sci. https://doi.org/10.1016/j.sjbs.2016. 11.01

Oyaizu M (1986) Studies on products of brownings reactionanioxidative activities of products of browning reaction prepared from glucosamine. Jpn J Nutr 44(6):307-315

Piwińska M, Wyrwisz J, Kurek M, Wierzbicka A (2016) Effect of oat $\beta$-glucan fiber powder and vacuum-drying on cooking quality and physical properties of pasta. Cyta J Food 14(1):101-108. https://doi.org/10.1080/19476337.2015.1052987

Re R, Pellegrini N, Proteggente A, Pannala A, Yang M, Rice-Evans C (1999) Antioxidant activity applying an improved ABTS radical cation decolorization assay. Free Radic Bio Med 26(9-10):1231-1237

Rekha MN, Chauhan AS, Prabhasankar P, Ramteke RS, Venkateswara Rao G (2013) Influence of vegetable purees on quality attributes of pastas made from bread wheat (T. aestivum). Cyta J Food 11(2):142-149. https://doi.org/10.1080/19476337.2012. 708881

Sant'Anna V, Christiano FDP, Marczak LDF, Tessaro IC, Thys RCS (2014) The effect of the incorporation of grape marc powder in fettuccini pasta properties. LWT Food Sci Technol 58(2):497-501. https://doi.org/10.1016/j.lwt.2014.04.008

Santagati NA, Salerno L, Attaguile G, Savoca F, Ronsisvalle G (2008) Simultaneous determination of catechins, rutin, and gallic acid in Cistus species extracts by HPLC with diode array detection. J Chromatogr Sci 46(2):150-156

Sęczyk Ł, Świeca M, Gawlik- Dziki U (2016) Effect of carob (Ceratonia siliqua L.) flour on the antioxidant potential, nutritional quality, and sensory characteristics of fortified durum wheat pasta. Food Chem 194:637-642. https://doi.org/10.1016/j. foodchem.2015.08.086

Singleton VL, Rossi JA (1965) Colorimetry of total phenolics with phosphomolybdic-phosphotungstic acid reagents. Am J Enol Vitic 16:144-158

Viapiana A, Konopacka A, Waleron K, Wesolowski M (2017) Cistus incanus L. commercial products as a good source of polyphenols in human diet. Ind Crop Prod 107:297-304. https://doi.org/10. 1016/j.indcrop.2017.05.066

Wójtowicz A, Mościcki L (2014) Influence of legume type and addition level on quality characteristics, texture and microstructure of enriched precooked pasta. LWT Food Sci Technol 59(2):1175-1185. https://doi.org/10.1016/j.lwt.2014.06.010

Wójtowicz A, Oniszczuk A, Oniszczuk T, Kocira S, Wojtunik K, Mitrus M, Kocira A, Widelski J, Skalicka-Woźniak K (2017) Application of Moldavian dragonhead (Dracocephalum moldavica L.) leaves addition as a functional component of nutritionally valuable corn snacks. Int J Food Sci Technol 54(10):3218-3229. https://doi.org/10.1007/s13197-017-2765-7

Wójtowicz A, Zalewska-Korona M, Jabłońska-Ryś E, SkalickaWoźniak K, Oniszczuk A (2018) Chemical characteristics and physical properties of functional snacks enriched with powdered tomato. Pol J Food Nutr Sci 68(3):251-261. https://doi.org/10. 1515/pjfns-2017-0028

Publisher's Note Springer Nature remains neutral with regard to jurisdictional claims in published maps and institutional affiliations. 